\title{
Effects of Different Processing Methods on the Antioxidant Activity of 6 Cultivars of Foxtail Millet
}

\author{
Lingyan Zhang, ${ }^{1,2}$ Jieying Li, ${ }^{2}$ Fei Han, ${ }^{3}$ Zhansheng Ding, ${ }^{2}$ and Liuping Fan ${ }^{1,2}$ \\ ${ }^{1}$ State Key Laboratory of Dairy Biotechnology, Technology Center, Bright Dairy \& Food Co. Ltd., Shanghai 200436, China \\ ${ }^{2}$ State Key Laboratory of Food Science and Technology, School of Food Science and Technology, Jiangnan University, \\ Wuxi 214122, China \\ ${ }^{3}$ Academy of State Administration of Grain, Beijing 100037, China
}

Correspondence should be addressed to Liuping Fan; fanliuping@jiangnan.edu.cn

Received 7 December 2016; Accepted 22 February 2017; Published 20 March 2017

Academic Editor: Hui-Min D. Wang

Copyright (c) 2017 Lingyan Zhang et al. This is an open access article distributed under the Creative Commons Attribution License, which permits unrestricted use, distribution, and reproduction in any medium, provided the original work is properly cited.

The total phenolic content (TPC) of millet was whole $>$ dehulled $>$ cooked $>$ steamed and the bound phenolic content $(\mathrm{BPC})$ was the main form. Compared with dehulled millet, the TPC, TFC, and phenolic acid contents were decreased significantly $(P<0.05)$. The retention rate of TPC of steamed millet ranged from $47 \%$ to $55 \%$ and cooked millet ranged from $55 \%$ to $79 \%$. Additionally, the mean cinnamic acid content of cooked millet was 1.29 times as much as steamed millet. The antioxidant activity of millet was whole $>$ dehulled $>$ cooked $>$ steamed. Therefore, cooked millet was a good choice for human.

\section{Introduction}

Foxtail millet (Setaria itatica), a member of the Poaceae grass family, is one of the world's oldest crops and is a valuable source of human food in Africa and Asia. Foxtail millet originates in the Yellow River Basin country, the main producing areas in China, accounting for $80 \%$ of world production [1]. India is the second largest producing areas of foxtail millet, accounting for $10 \%$ of world production. The foxtail millet mainly in arid and semiarid regions in the north is one of the major food crops in northern China [2].

Phenolic compounds of millet, presented in free and bound forms, are ubiquitous which possess health benefits such as antioxidant and antimicrobial properties [3, 4]. At present, most papers have reported the nutritional composition of millet without processing $[5,6]$ and some papers focused on the effects of dehulling or milling on the nutrients or antioxidant activity of millet [7-12]. Singh and Srivastava [5] reported that the nutritional composition including minerals and antinutritional factors of finger millet (Africa) and the variety "VL-204" was found to be exceptionally rich in iron and very low in antinutritional factor phytate content. Bachar et al. [6] also reported calcium and magnesium were the most concentrated nutrients in all finger millet, followed by potassium, sodium, and phosphorus. Chandrasekara and Shahidi [7] also showed Kodo millet (Sri Lanka) had the highest total phenolic content, up to $114.03 \pm 1.08 \mu \mathrm{mol}$ of ferulic acid equiv/g of defatted meal, and all millet varieties showed high antioxidant activities. Choi et al. [4] reported that the polyphenolics content of the methanolic extracts obtained from whole millet (Morejo) was $47 \pm 1.4 \mathrm{mg}$ GAE/100 g of grain (wet weight basis). Zhang and Liu [12] reported the phenolic compounds and antioxidant activity of two cultivars (China) of dehulled foxtail millet. However, there were few researches on the effect of steaming and cooking on phenolic compounds and antioxidant activity of millet, which were the main homely cuisine ways in China or other countries. Thus, the primary objectives of this study were to entirely discuss the effect of different processing methods of dehulling, cooking, and steaming on the nutraceutical of FPC, BPC, phenolic acid, the free flavonoid contents (FFC), bound flavonoid contents (BFC), and phytic acid contents 
of 6 cultivars of foxtail millet planted in China, further investigating the changes of their antioxidant activity and their correlation with the nutraceutical.

\section{Materials and Methods}

2.1. Raw Material. The 6 cultivars of foxtail millet, which were Yugu01 (Henan province), Jingfen02 (Shanxi province), Jinggu21 (Shanxi province), Fenghonggu (Inner Mongolia province), Jigu31 (Hebei province), and Longgu12 (Gansu province), were selected for analysis in this experiment. The samples in the experiment are well representative, no sample wormhole, mildew, groats, in which there is no pollution and no hybridization of pure millet.

2.2. Sample Preparation. Foxtail millet was dehulled three times by the huller under the power of $2 \mathrm{kw}$. After the dehulling, the ratio of hull removal was $90 \%$. After washing and draining, the millet was cooked at $100^{\circ} \mathrm{C}$ for $30 \mathrm{~min}$ and the ratio of seed: water was $1: 20(\mathrm{w} / \mathrm{w})$ [13]. The steaming millet was processed at $100^{\circ} \mathrm{C}$ for $10 \mathrm{~min}$ and seed : water ratio $1: 5(\mathrm{w} / \mathrm{w})[14,15]$. After cuisine, the cooked and steamed millet were prefrozen in a cold room $\left(-80^{\circ} \mathrm{C}, 4 \mathrm{~h}\right)$ and then lyophilized to dryness and milled with a coffee mill. The flour was passed through an 80-mesh sieve and stored in refrigerator $\left(-20^{\circ} \mathrm{C}\right)$ until analyzed.

2.3. Extraction of Free Phenolic Compounds. Free phenolic compounds were extracted using the method as described by Taylor and Duodu [11] and Xu and Chang [16] with modifications. Free phenolic compounds in grains were extracted by blending $15 \mathrm{~g}$ of whole grain flour with $180 \mathrm{~mL}$ of solvent (the ratio of absolute ethanol : water : acetic acid was $70: 29.5: 0.5$, $\mathrm{v} / \mathrm{v} / \mathrm{v}$ ) for $4 \mathrm{~h}$ at $45^{\circ} \mathrm{C}$. After centrifugation at $5000 \mathrm{r} / \mathrm{min}$ for $10 \mathrm{~min}$, the supernatant was pooled, evaporated at $50^{\circ} \mathrm{C}$ to $10 \mathrm{~mL}$, reconstituted with methanol to a final volume of $25 \mathrm{~mL}$, and stored at $4^{\circ} \mathrm{C}$ until analysis. The residues were lyophilized.

2.4. Extraction of Bound Phenolic Compounds. Bound phenolic compounds were extracted using the method as described by Adom and Liu [17] with modifications. Briefly, $1.0000 \mathrm{~g}$ of the residues after extracted free phenolic compounds was then digested with $18 \mathrm{~mL}$ of $1.5 \mathrm{M}$ sodium hydroxide at room temperature for $1 \mathrm{~h}$ with shaking under nitrogen gas. The mixture was neutralized with $6 \mathrm{M}$ hydrochloric acid until the $\mathrm{pH}$ value up to 2 and extracted with hexane $(4 \times 10 \mathrm{~mL}, 30 \mathrm{~min})$ to remove lipids. The final solution was extracted with ethyl acetate $(4 \times 10 \mathrm{~mL}, 30 \mathrm{~min})$. The ethyl acetate fraction was evaporated to dryness. Phenolic compounds were reconstituted in $5 \mathrm{~mL}$ of methanol.

2.5. Determination of Total Phenolic Content. Total phenolic contents of the extracts were determined using FolinCiocalteu colorimetric method as described by Singleton et al. [18] with modifications. Briefly, $1 \mathrm{~mL}$ of foxtail millet extract was oxidized with $1 \mathrm{~mL}$ of Folin-Ciocalteu reagent, and the reaction was neutralized with sodium carbonate. The resulting blue color was reconstituted with methanol to a final volume of $10 \mathrm{~mL}$ and the absorbance was measured at $760 \mathrm{~nm}$ after $2 \mathrm{~h}$. Total phenolic content was expressed as mg gallic acid equivalents/100 g dry weight (mg GAE/100 g DW). Data are reported as a mean value \pm standard deviation (SD) for three replications.

2.6. Determination of Phenolic Acid. Phenolic acid contents were determined by HPLC equipped with an autosampler and a diode-array detector. The analytical column was Agilent ZORBAX SB-C18. The mobile phase consisted of $0.05 \%$ TFA in water (v/v) (solvent $\mathrm{A}$ ) and $0.05 \%$ TFA in acetonitrile (solvent $\mathrm{B}$ ). The flow rate was kept at $0.8 \mathrm{~mL} / \mathrm{min}$. The injection volume was $20 \mu \mathrm{L}$ and peaks were monitored simultaneously at $260 \mathrm{~nm}$. All samples were filtered through a $0.45 \mu \mathrm{m}$ filter before injection. Values were expressed as $\mu \mathrm{g} / \mathrm{g}$ DW.

2.7. Determination of Total Flavonoid Content. Total flavonoid contents of the extracts were determined using the method as described by Singleton et al. [18] with modifications. Briefly, appropriate dilutions of sample extracts were reacted with $3 \mathrm{~mL}$ of aqueous solution of $1 \mathrm{M}$ potassium acetate, followed by a flavonoid-aluminum complex formation using $2 \mathrm{~mL}$ of aqueous solution of $0.1 \mathrm{M}$ aluminum chloride. The sample was reconstituted with $30 \%$ ethanol to a final volume of $10 \mathrm{~mL}$. The absorbance at $420 \mathrm{~nm}$ was measured after $0.5 \mathrm{~h}$ and the result was expressed as $\mathrm{mg}$ rutin equivalents/100 g dry weight (mg RE/100 g DW). Data are reported as a mean value \pm standard deviation $(\mathrm{SD})$ for three replications.

2.8. Determination of Phytic Acid Content. The phytic acid contents of the 6 cultivars of foxtail millet were determined using the method as described by Badau et al. [19] and Wheeler and Ferrel [20].

The absorbance at $480 \mathrm{~nm}$ was measured and the result was expressed as $\mathrm{mg} / \mathrm{g}$ dry weight (mg/g DW). Data are reported as a mean value \pm standard deviation $(\mathrm{SD})$ for three replications.

2.9. Determination of Antioxidant Activity. For ABTS assay, the procedure followed the method of Arnao et al. [21] and Thaipong et al. [22]. The FRAP assay was carried out according to Thaipong et al. [22].

The DPPH assay was carried out according to BrandWilliams et al. [23] with some modifications. The stock solution was prepared by dissolving $19.716 \mathrm{mg}$ DPPH with $50 \mathrm{~mL}$ anhydrous methanol and then stored at $-20^{\circ} \mathrm{C}$ until needed. The working solution was obtained by mixing $1 \mathrm{~mL}$ stock solution with $9 \mathrm{~mL}$ anhydrous methanol to obtain an absorbance of $1.1 \pm 0.02$ units at $515 \mathrm{~nm}$ using the spectrophotometer. Foxtail millet extracts $(200 \mu \mathrm{L})$ were all owed to react with $3.8 \mathrm{~mL}$ of $0.1 \mathrm{M} \mathrm{DPPH}$ solution for $0.5 \mathrm{~h}$ in the dark. The absorbance at $765 \mathrm{~nm}$ was measured. The standard curve was linear between 50 and $500 \mu \mathrm{M}$ Trolox and the results were expressed in $\mu \mathrm{mol}$ Trolox equivalents/g dry weight $(\mu \mathrm{mol} \mathrm{TE} / \mathrm{g} \mathrm{DW})$. Data are reported as a mean value \pm standard deviation (SD) for three replications.

The ORAC procedure, measuring a compounds ability to scavenge a free radical from ABAP compared to that Trolox, 


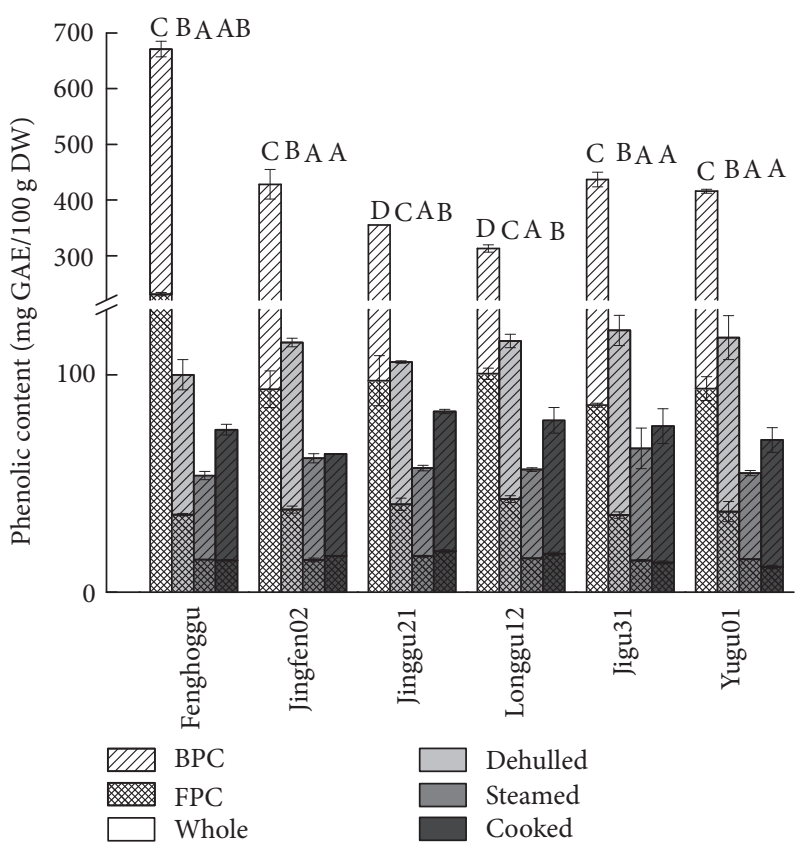

FIgURE 1: The FPC, BPC, and TPC of 6 cultivars of foxtail millet with different treatment. Error bars represent the standard deviation $( \pm \mathrm{SD})$. The different uppercase letters $(A-D)$ indicate significant differences of TPC within different processing methods of the same cultivar $(P<0.05)$.

used an automated plate reader with 96-well plates [24]. Briefly, $40 \mu \mathrm{L}$ phosphate buffer was pipetted to the F well and $20 \mu \mathrm{L}$ sample, blank (phosphate buffer), or Trolox standard was, respectively, pipetted to the appropriate well except the $\mathrm{F}$ and incubated $10 \mathrm{~min}$ at $37^{\circ} \mathrm{C}$. Then add $200 \mu \mathrm{L}$ fluorescein working solution to each well. Add $20 \mu \mathrm{L}$ AAPH working solution to each well after $20 \mathrm{~min}$ and read plate immediately. Fluorescence conditions were as follows: excitation at $485 \mathrm{~nm}$ and emission at $538 \mathrm{~nm}$. The standard curve was linear between 0 and $50 \mu \mathrm{M}$ Trolox and the results were expressed in $\mu \mathrm{mol}$ Trolox equivalents/g dry weight ( $\mu \mathrm{mol}$ TE/g DW). Data are reported as a mean value \pm standard deviation (SD) for three replications.

2.10. Statistical Analysis. The analysis of variance (ANOVA) technique was used to analyze the experimental data and Duncan's multiple range tests were used to determine the significance of differences among treatments at 95\% confidence level. Correlations among data were calculated using Pearson's correlation coefficient $(r)$.

\section{Results and Discussion}

3.1. Effects of Processing Methods on the Phenolic Content of Foxtail Millet. The free phenolic contents (FPC), bound phenolic contents (BPC), and total phenolic contents (TPC) of the 6 cultivars of foxtail millet with different treatment were shown in Figure 1, which have significant difference $(P<0.05)$. For the different processing methods of foxtail millet, the TPC were whole $>$ dehulled $>$ cooked $>$ steamed.
In whole foxtail millet, the FPC and BPC of Fenghonggu were higher than the other millets, up to $230.95 \pm 3.26$ and 440.14 $\pm 13.86 \mathrm{mg}$ GAE$/ 100 \mathrm{~g} \mathrm{DW}$, respectively. At the same time, Longgu12 showed the lowest content. The different cultivars may be responsible for these results.

The FPC accounted for $26.34 \%$ (ranging from $19.72 \%$ to $34.41 \%$ ), $34.18 \%$ (ranging from $29.45 \%$ to $38.18 \%$ ), $26.41 \%$ (ranging from $22.09 \%$ to $28.88 \%$ ), and $20.90 \%$ (ranging from $16.59 \%$ to $26.33 \%$ ) of the TPC in whole, dehulled, steamed, and cooked foxtail millet. Thus the phenolic compounds existed mainly in the bound form, which was consistent with Zhang and Liu [12] who showed that FPC constituted around $32 \%$ and $38 \%$ of the TPC in Jingu 28 and Jingu34, respectively. In addition, Adom and Liu [17] showed the FPC contributed $15 \%$ of the total in corn, $24 \%$ in wheat, $25 \%$ in oats, and $38 \%$ in rice. This may be due to the different grain.

When the foxtail millet was dehulled, the phenolic contents had a significant reduction $(P<0.05)$. The TPC of Jigu31 (120.53 $\pm 8.45 \mathrm{mg}$ GAE/100 $\mathrm{g} \mathrm{DW})$ and Yugu01 $(117.22 \pm 19.73 \mathrm{mg}$ GAE/100 g DW) were higher than other dehulled foxtail millets. In dehulled foxtail millet, the mean value of TPC was $112.42 \mathrm{mg}$ GAE/100 g DW which was slightly higher than the results of Zhang and Liu [12] who reported that the mean TPC of Jingu 28 and Jingu34 were $96.51 \mathrm{mg} \mathrm{GAE} / 100 \mathrm{~g}$ DW. The TPC of dehulled foxtail millet constituted around $15 \%$ and $37 \%$ of the TPC of whole foxtail millet in Fenghonggu and Longgu12, respectively. Kim et al. [25] and Vaher et al. [26] reported that the phenolic compounds were mainly found in the bran. Ivanišová et al. [9] reported that $73 \%$ of grain phenolic contents were found in the bran. Thus the results of this study gave further support to the notion that phenolic compounds of grains were concentrated mainly in the bran.

The TPC were ranged from $53.70 \pm 1.97$ (Fenghonggu) to $66.23 \pm 9.60$ (Jigu31) $\mathrm{mg}$ GAE/100 g DW in steamed foxtail millet with a mean value of $58.38 \mathrm{mg}$ GAE/100 $\mathrm{g} \mathrm{DW}$. Compared with dehulled millet, the retention rate of TPC of steamed millet ranged from 47\% (Yugu01) to 55\% (Jigu31). In cooked foxtail millet, the TPC were ranged from $63.61 \pm$ 0.25 to $83.19 \pm 1.78 \mathrm{mg}$ GAE/100 g DW with a mean value of $74.54 \mathrm{mg} \mathrm{GAE} / 100 \mathrm{~g}$ DW. Compared with dehulled millet, the retention rate of TPC of cooked millet ranged from 55\% (Jiingfen02) to 79\% (Jinggu21). The different TPC may be due to the different ratio of seed: water involved in steamed and cooked foxtail millet. Additionally, the FPC and BPC of millets decreased significantly after cooking and steaming $(P<0.05)$. The heating process involved in steamed and cooked foxtail millet might be responsible for the reduced level of the FPC and BPC. Compared with cooked millet, the BPC of steamed millet decreased significantly $(P<0.05)$, which may be because the moisture activity and oxygen concentration were different. Meanwhile, a part of bound phenolic degraded into free phenolic and the free phenolic could be oxidized easier in the high concentration of the moisture and oxygen; thus the FPC of steamed and cooked millet had no significant difference $(P<0.05)$.

3.2. Effects of Processing Methods on the Phenolic Acid Composition. The phenolic acids compositions of 6 cultivars of 
TABLE 1: Phenolic acid composition of 6 cultivars of whole foxtail millet.

\begin{tabular}{|c|c|c|c|c|c|c|}
\hline Phenolic acid & Coumaric acid & $P$-Hydroxy benzoic acid & Vanillic acid & Caffeic acid & Cinnamic acid & Ferulic acid \\
\hline Longg12 & $75.15 \pm 0.11$ & $108.89 \pm 1.26$ & $63.31 \pm 0.98$ & $5.67 \pm 0.01$ & $2075.03 \pm 25.78$ & $0.89 \pm 0.00$ \\
\hline Jigu31 & $105.18 \pm 1.23$ & $22.50 \pm 0.02$ & $271.31 \pm 8.23$ & $3.70 \pm 0.01$ & $3128.72 \pm 19.08$ & $6.17 \pm 0.01$ \\
\hline Yugu01 & $61.91 \pm 1.01$ & $12.87 \pm 0.01$ & $74.56 \pm 0.63$ & $1.07 \pm 0.01$ & $1837.38 \pm 10.01$ & $1.67 \pm 0.00$ \\
\hline Jinggu21 & $180.39 \pm 3.27$ & $19.53 \pm 0.25$ & $109.85 \pm 0.16$ & $6.18 \pm 0.02$ & $1995.29 \pm 9.87$ & $2.49 \pm 0.01$ \\
\hline Jingfen02 & $334.60 \pm 9.01$ & $15.02 \pm 0.01$ & $122.25 \pm 1.21$ & $3.08 \pm 0.01$ & $1828.43 \pm 21.01$ & $2.33 \pm 0.01$ \\
\hline Fenghonggu & $116.36 \pm 1.06$ & $30.90 \pm 0.78$ & $167.72 \pm 1.85$ & $4.96 \pm 0.05$ & $2091.76 \pm 13.47$ & $13.33 \pm 0.01$ \\
\hline
\end{tabular}

Values expressed as $\mu \mathrm{g} / \mathrm{g}$ DW. Values are means $\pm \mathrm{SD}$ of three determinations.

whole millet which were coumaric acid, $P$ - hydroxy benzoic acid, vanillic acid, caffeic acid, cinnamic acid, and ferulic acid were presented in Table 1 . In the 6 kinds of phenolic acids, cinnamic acid was higher than any others in 6 cultivars of whole millet, ranged from 1828.43 (Jingfen02) to 3128.72 (Jigu31) $\mu \mathrm{g} / \mathrm{g}$ DW, and accounted for $87 \%$ of the 6 kinds of phenolic acids. The result was higher than the report of Mcdonough et al. [27] who showed that the contents of cinnamic acid of foxtail millet, pearl millet, and finger millet were $781.7,345.3$, and $35.1 \mu \mathrm{g} / \mathrm{g}$, respectively. In addition, the values of vanillic acid and coumaric acid were relatively higher. The vanillic acid of whole foxtail millet ranged from 63.31 to $271.31 \mu \mathrm{g} / \mathrm{g} \mathrm{DW}$, accounting for $5 \%$ of the 6 kinds of phenolic acids. The coumaric acid of whole foxtail millet ranged from 61.91 to $334.60 \mu \mathrm{g} / \mathrm{g} \mathrm{DW}$, accounting for $6 \%$ of the 6 kinds of phenolic acids, which were different with Chandrasekara and Shahidi [7] who showed that $p$-coumaric acids of Kodo, finger (Ravi), finger (local), foxtail, proso, little, and pearl millets were $698.67,37.56,39.81,915.90,1155.40$, 1027.26 , and $41.45 \mu \mathrm{g} / \mathrm{g}$ of defatted meal, respectively. This may be due to the different cultivars and different planting region.

When the foxtail millets were dehulled, steamed, and cooked, coumaric acid, $P$-hydroxy benzoic acid, vanillic acid, and caffeic acid were hard to detect in 6 cultivars of foxtail millet. Figure 2 showed the contents of cinnamic acid and ferulic acid of 6 cultivars of foxtail millet with different treatment and that they had significant differences $(P<0.05)$. The heat treatment in wetted preparations may cause phenolic acid to decrease. The cinnamic acids of cooked millet were $46.27 \%$ lower than dehulled foxtail millet, ranging from $26.47 \%$ (Longgul2) to $69.27 \%$ (Jinfen02). For the steamed millet, the range $(46.09 \%$ to $63.12 \%)$ was different from cooked millet. However, the mean cinnamic acid content of cooked millet was 1.29 times as much as steamed millet. As Figure 2(b) has shown, the ferulic acids of cooked and steamed millet were $83.40 \%$ and $42.07 \%$ lower than dehulled millet, respectively. However, the mean ferulic acid content of cooked millet was 3.42 times as much as steamed millet. This may be due to the different ratio of seed : water and processing time.

3.3. Effects of Processing Methods on the Flavonoid Content. Flavonoid presented in grains had potent antioxidant properties associated with the health benefits of grains and grain products [17]. The flavonoid contents of the 6 varieties of foxtail millet, expressed as $\mathrm{mg}$ rutin equivalents $/ 100 \mathrm{~g}$ of dried foxtail millet weight, were shown in Figure 3. Significant differences were found in the free flavonoid contents (FFC), bound flavonoid contents (BFC), and total flavonoid contents (TFC) between whole and dehulled foxtail millet $(P<0.05)$. In whole foxtail millet, the FFC of Jigu31 was lower than any other cultivars and the BFC of Fenghonggu was lower than others, but the TFC of Jigu31 was lowest. The different cultivars may be responsible for these results.

In dehulled foxtail millet, the TFC were ranged from $485.25 \pm 26.01$ (Yugu01) to $620.77 \pm 18.43$ (Fenghonggu) $\mathrm{mg}$ $\mathrm{RE} / 100 \mathrm{~g}$ DW with a mean value of $577.52 \mathrm{mg} \mathrm{RE} / 100 \mathrm{~g} \mathrm{DW}$, which were 4 to 6 times that of whole millet. The TFC of dehulled foxtail millet were significantly $(P<0.05)$ higher than whole foxtail millet, because of the conversion of the major flavones into the C-glycosylflavanols form in the seeds [28].

Compared with dehulled foxtail millet, cooking and steaming were significantly $(P<0.05)$ increased in the BFC for the 6 cultivars of foxtail millet. The BFC of steamed foxtail millet were $31 \%$ higher than dehulled foxtail millet, ranging from $0.3 \%$ (Jinfen02) to $96 \%$ (Jigu31). The BFC of cooked foxtail millet were $23 \%$ higher than dehulled foxtail millet, ranging from $2 \%$ (Jingfen02) to $74 \%$ (Jigu31). In contrast, the FFC of steamed and cooked foxtail millet were lower than dehulled foxtail millet. The FFC of dehulled foxtail millet were ranged from $189.86 \pm 11.77$ (Yugu01) to 379.83 \pm 1.39 (Fenghonggu) $\mathrm{mg} \mathrm{RE} / 100 \mathrm{~g} \mathrm{DW}$ with a mean value of $301.26 \mathrm{mg} \mathrm{RE} / 100 \mathrm{~g}$ DW. However, the FFC of cooked foxtail millet were ranged from $23.66 \pm 2.81$ (Longgu12) to $120.41 \pm 0.42$ (Jingfen02) $\mathrm{mg} \mathrm{RE} / 100 \mathrm{~g}$ DW with a mean value of $86.93 \mathrm{mg} \mathrm{RE} / 100 \mathrm{~g}$ DW. The FFC of steamed foxtail millet were ranged from $42.95 \pm 0.54$ (Longgu12) to 149.83 \pm 7.82 (Fenghonggu) $\mathrm{mg} \mathrm{RE} / 100 \mathrm{~g}$ DW with a mean value of $86.61 \mathrm{mg} \mathrm{RE} / 100 \mathrm{~g}$ DW. Cooking and steaming involving heat treatment seemed to be extremely important for reducing the FFC of the 6 cultivars of foxtail millet [29]. Additionally, the heat treatment in wetted preparations could favour the hydrolysis of C-glycosylflavones and the release of corresponding aglycones, which led to an increase in the BFC of cooked and steamed foxtail millet [30, 31].

For the cooked and steamed millet, the TFC of Jigu31, Yugu01, and Jinggu21 had no significant difference $(P<0.05)$. For Jingfen02, the TFC of cooked millet was 1.06 times as 


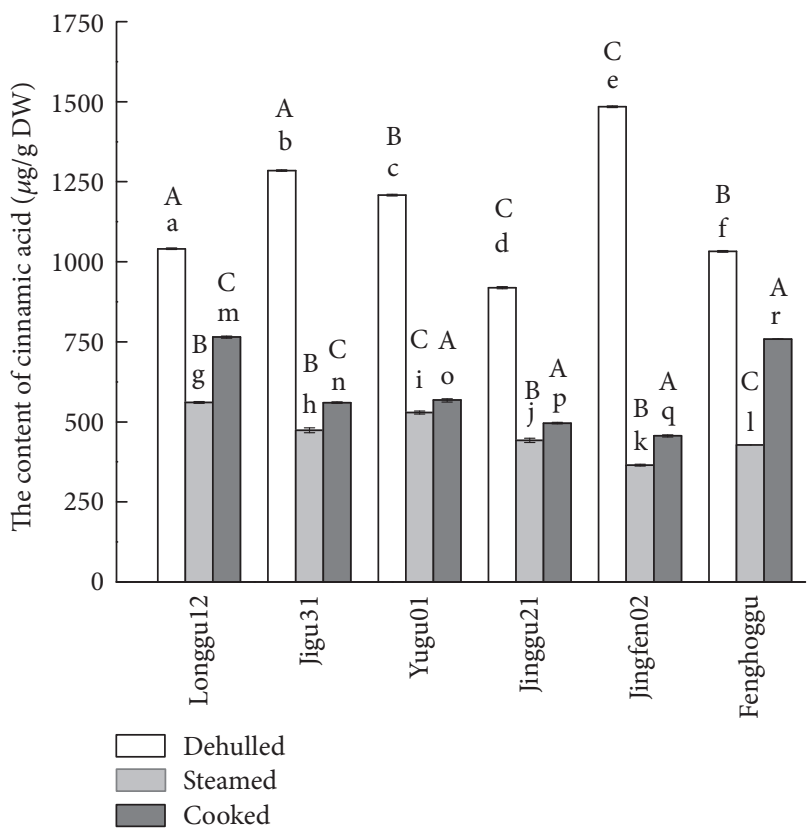

(a)

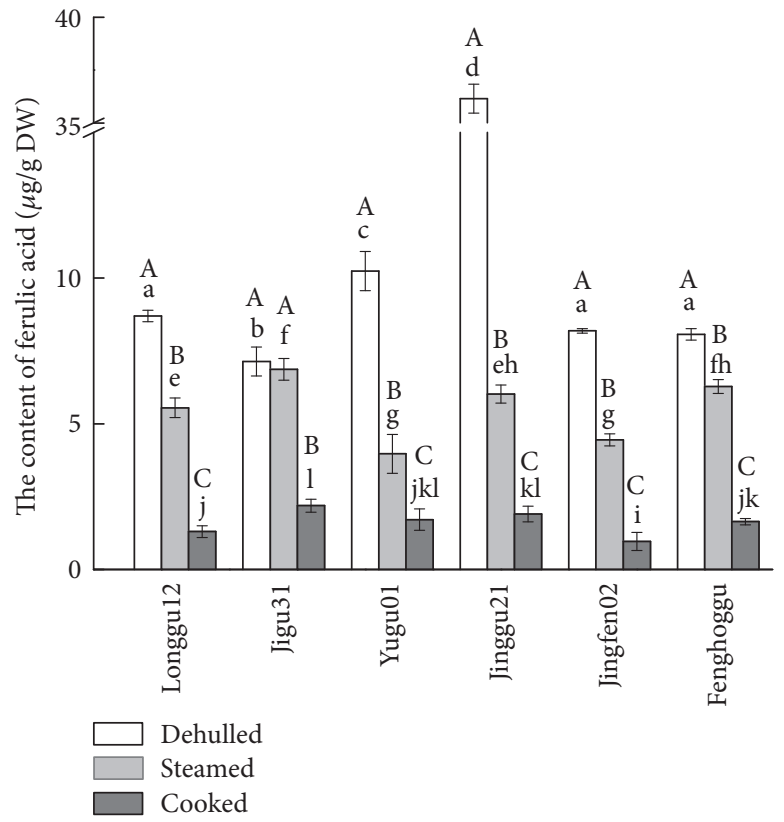

(b)

FIGURE 2: (a) The cinnamic acid of 6 cultivars of foxtail millet with different treatment. Error bars represent the standard deviation $( \pm$ SD). The different uppercase letters $(A-C)$ indicate significant differences within different processing methods of the same cultivar $(P<0.05)$. The different lowercase letters $(a-r)$ indicate significant differences within different cultivars with the same treatment $(P<0.05)$. (b) The ferulic acid of 6 cultivars of foxtail millet with different treatment. Error bars represent the standard deviation $( \pm \mathrm{SD})$. The different uppercase letters $(A-C)$ indicate significant differences within different processing methods of the same cultivar $(P<0.05)$. The different lowercase letters $(a-l)$ indicate significant differences within different cultivars with the same treatment $(P<0.05)$.

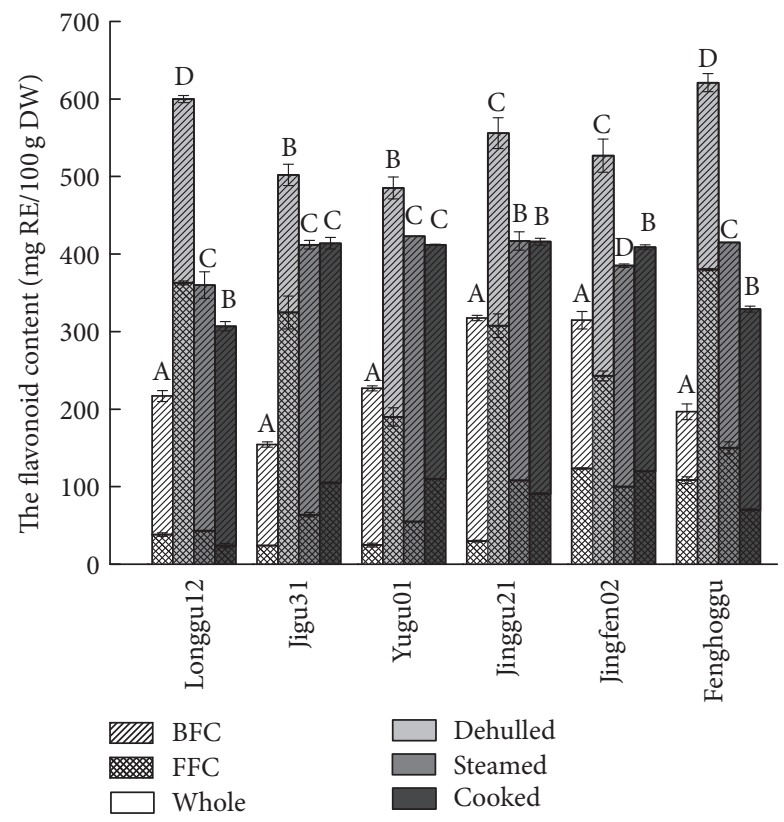

Figure 3: The FFC, BFC, and TFC of 6 cultivars of foxtail millet with different treatment. Error bars represent the standard deviation $( \pm \mathrm{SD})$. The different uppercase letters $(A-D)$ indicate significant differences of TFC within different processing methods of the same cultivar $(P<0.05)$. much as steamed millet. For Longgu12 and Fenghonggu, the TFC of cooked millet accounted for $85 \%$ and $79 \%$ of the TFC of steamed millet, which may be the result of the different processing time.

\subsection{Effects of Processing Methods on the Phytic Acid Content.} The phytic acid contents of whole, dehulled, steamed, and cooked foxtail millet were presented in Figure 4. Significant differences in the phytic acid contents among Longgu12, Jigu31, Yugu01, Jinggu21, and Fenghonggu were observed $(P<0.05)$. The phytic acid contents of whole foxtail millet ranged from $27.96 \pm 0.01$ (Yugu01) to $28.95 \pm 0.04$ (Jinfen02) $\mathrm{mg} / \mathrm{g} \mathrm{DW}$. Thus the results of this study were not consistent with El Hag et al. [32] who reported that the phytic acid contents of two cultivars of whole pearl millet were $9.43 \pm$ 0.04 and $10.76 \pm 0.16 \mathrm{mg} / \mathrm{g}$, respectively. As a result of the analysis, the phytic acid contents of 6 cultivars of dehulled foxtail millet were $2.80 \%$, which were consistent with Badau et al. [19] who reported that the phytic acid content of ten pearl millet cultivars ranged from $2.91 \%$ to $3.30 \%$. This might be due to the fact that phytic acid content varied depending upon the cultivar, irrigation conditions, and type of soil in which they were grown [33].

Phytic acid had the ability to form insoluble chelates with various metal ions such as iron, zinc, and calcium [34]. When cooking and steaming, the phytic contents of 6 cultivars of 


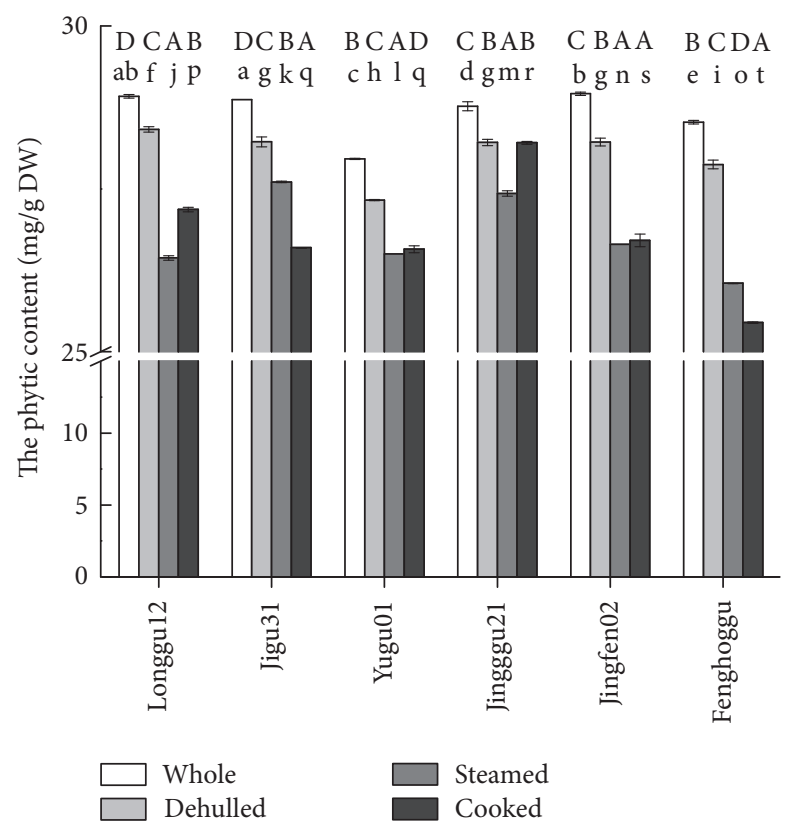

FIgURE 4: Phytic acid contents of 6 cultivars of foxtail millet with different treatment. Error bars represent the standard deviation $( \pm \mathrm{SD})$. The different uppercase letters $(A-D)$ indicate significant differences within different processing methods of the same cultivar $(P<0.05)$. The different lowercase letters $(a-t)$ indicate significant differences within different cultivars with the same treatment $(P<$ $0.05)$.

foxtail millet reduced. The phytic acid contents of steamed foxtail millet ranged from $26.05 \pm 0.01$ to $27.61 \pm 0.01 \mathrm{mg} / \mathrm{g}$ DW. The phytic acid contents of cooked foxtail millet ranged from $25.45 \pm 0.01$ to $28.21 \pm 0.03 \mathrm{mg} / \mathrm{g}$ DW. The phytic acid contents of cooked and steamed foxtail millet were $4.49 \%$ and 4.51\% lower than dehulled millet. This might be due to the fact that any formation of calcium/magnesium salts of phytic acid, compounds with limited solubility, occurs as a result of heat treatment $[35,36]$.

3.5. Effects of Processing Methods on the Antioxidant Activity. The antioxidant potential of 6 varieties of foxtail millet was determined on the basis of the scavenging activity of the stable free radicals DPPH, FRAP, ABTS, and ORAC (Tables 2(a) and 2(b)). Significant differences within different processing methods of the same cultivar in the antioxidant activity measured by DPPH, FRAP, and ABTS assays were observed $(P<0.05)$. The value of DPPH-measured antioxidant activity was ranged from $0.93 \pm 0.03$ (steamed foxtail millet) to 4.74 \pm 0.06 (whole foxtail millet) $\mu \mathrm{mol} \mathrm{TE} / \mathrm{g}$ DW.

For the different processing methods of foxtail millet, the antioxidant activity, measured by DPPH and FRAP, was whole $>$ dehulled $>$ cooked $>$ steamed. Jigu31, whole foxtail millet, showed the highest antioxidant activity compared to the other cultivars when measured by FRAP (26.94 \pm $0.61 \mu \mathrm{mol} \mathrm{TE} / \mathrm{g} \mathrm{DW}), \mathrm{DPPH}(4.74 \pm 0.06 \mu \mathrm{mol} \mathrm{TE} / \mathrm{g} \mathrm{DW})$, ABTS (59.92 $\pm 0.04 \mu \mathrm{mol} \mathrm{TE} / \mathrm{g} \mathrm{DW})$, and ORAC (624.1 $\pm 2.79 \mu \mathrm{mol} \mathrm{TE} / \mathrm{g} \mathrm{DW}$ ) assays. By contrast, Yugu01, whole foxtail millet, showed the lowest antioxidant activity when measured by FRAP $(16.60 \pm 0.62 \mu \mathrm{mol}$ TE/g DW), DPPH $(4.38 \pm 0.02 \mu \mathrm{mol} \mathrm{TE} / \mathrm{g} \mathrm{DW})$, and ABTS $(41.76 \pm 3.14 \mu \mathrm{mol}$ TE/g DW) assays. However, for dehulled foxtail millet, Yugu01 showed the highest antioxidant activity compared to the other cultivars when measured by FRAP $(7.75 \pm 0.17 \mu \mathrm{mol}$ TE/g DW), DPPH (4.02 $\pm 0.11 \mu \mathrm{mol} \mathrm{TE} / \mathrm{g}$ DW), ABTS (15.24 $\pm 0.36 \mu \mathrm{mol} \mathrm{TE} / \mathrm{g} \mathrm{DW})$, and ORAC $(182.2 \pm 40.21 \mu \mathrm{mol} \mathrm{TE} / \mathrm{g}$ DW) assays. The antioxidants of cooked and steamed millet, measured by DPPH, FRAP, ABTS, and ORAC assays, were not consistent with each other, which may be because ABTS, FRAP, and DPPH were measured single electron transfer and ORAC represented hydrogen atom transfer [37]. Therefore, antioxidant potency composite index (APC) was used to measure the antioxidant activity of 6 cultivars of foxtail millet [38].

Table 2(c) showed that the antioxidant activity of millet was whole $>$ dehulled $>$ cooked $>$ steamed and the mean APC of whole, dehulled, steamed, and cooked millet were $0.83,0.33,0.20$, and 0.21 , respectively. Additionally, the rank order of antioxidant activity of dehulled millet was Yugu01 $>$ Jigu31 $>$ Jingfen02 > Jinggu21 $>$ Longgul2 $>$ Fenghonggu. However, the antioxidant activity of steamed foxtail millet was consistent with cooked foxtail millet. The rank order of antioxidant activity was Fenghonggu $>$ Longgu12 $>$ Jinggu21 $>$ Yugu01 $>$ Jigu31 $>$ Jingfen02. The reason might be the fact that cooking and steaming involving heat treatment led to reducing the polyphenols of the 6 cultivars of foxtail millet in various degrees.

3.6. Correlations. Total phenolics of the foxtail millet (FolinCiocalteu method) correlated strongly with their antioxidant activity measured by all four methods $(P<0.01)$. The correlation coefficients were as follows: TPC versus DPPH, $r$ $=0.83$; TPC versus ABTS, $r=0.91$; TPC versus FRAP, $r=0.91$; TPC versus ORAC, $r=0.87$ (Table 3), which was consistent with previous findings that there was significant correlation between TPC and antioxidant [20]. Awika et al. [39] reported that phenol contents of the sorghums correlated strongly with their antioxidant activity measured by DPPH, ABTS, and ORAC assays and the correlation coefficients were as follows: phenol versus ORAC, $r=0.96$; phenol versus ABTS, $r=$ 0.97; phenol versus DPPH, $r=0.96$. In addition, correlations among the antioxidant activities measured by ABTS, DPPH, FRAP, and ORAC assays and CA were positively high and ranged between 0.75 and 0.89. FRAP, ABTS, and ORAC values were significantly correlated $(P<0.01)$. MorenoMontoro et al. [40] also reported significant correlation between FRAP and ABTS values.

\section{Conclusion}

From the data in this study, it can be concluded that the different processing methods of foxtail millet made an effect on the TPC, TFC, and the 6 kinds of phenolic acids. Compared with whole millet, the TPC of dehulled millet decreased and TFC of dehulled millet increased. Compared with dehulled millet, the TPC and TFC of cooked and steamed millet decreased. However, the total phenolic content and cinnamic acid content were rich in cooked millet. In addition, cooked 
TABLE 2: (a) The antioxidant activity of 6 cultivars of foxtail millet with different treatment measured by the FRAP and DPPH methods. (b) The antioxidant activity of 6 cultivars of foxtail millet with different treatment measured by the ABTS and ORAC methods. (c) Antioxidant potency composite index of 6 cultivars of foxtail millet with different treatment.

(a)

\begin{tabular}{|c|c|c|c|c|c|c|c|c|}
\hline \multirow{2}{*}{ Foxtail millet } & \multicolumn{4}{|c|}{ FRAP } & \multicolumn{4}{|c|}{ DPPH } \\
\hline & Whole & Dehulled & Steamed & Cooked & Whole & Dehulled & Steamed & Cooked \\
\hline Longg12 & $20.06 \pm 0.03^{\mathrm{dC}}$ & $6.59 \pm 0.09^{c C}$ & $3.92 \pm 0.23^{\mathrm{aB}}$ & $5.11 \pm 0.13^{\mathrm{bC}}$ & $4.63 \pm 0.06^{\mathrm{dC}}$ & $2.34 \pm 0.11^{\mathrm{cB}}$ & $1.50 \pm 0.02^{\mathrm{b}}$ & $1.77 \pm 0.03^{\mathrm{aA}}$ \\
\hline Jigu31 & $26.94 \pm 0.61^{\mathrm{dD}}$ & $7.16 \pm 0.14^{\mathrm{cD}}$ & $4.11 \pm 0.19^{\mathrm{aB}}$ & $4.89 \pm 0.21^{\mathrm{bC}}$ & $4.74 \pm 0.06^{\mathrm{dC}}$ & $3.14 \pm 0.15^{\mathrm{cC}}$ & $1.37 \pm 0.02^{\mathrm{bB}}$ & $1.70 \pm 0.05^{\mathrm{aB}}$ \\
\hline Yugu01 & $16.60 \pm 0.62^{\mathrm{dA}}$ & $7.75 \pm 0.17^{\mathrm{cE}}$ & $4.09 \pm 0.09^{\mathrm{bC}}$ & $4.57 \pm 0.04^{\mathrm{aA}}$ & $4.38 \pm 0.02^{\mathrm{dA}}$ & $4.02 \pm 0.11^{\mathrm{cE}}$ & $0.93 \pm 0.03^{\mathrm{bD}}$ & $2.03 \pm 0.01^{\mathrm{aC}}$ \\
\hline Jinggu21 & $20.48 \pm 1.61^{\mathrm{cC}}$ & $5.79 \pm 0.08^{\mathrm{bB}}$ & $3.80 \pm 0.06^{\mathrm{aB}}$ & $4.19 \pm 0.23^{\mathrm{aB}}$ & $4.60 \pm 0.10^{\mathrm{dBC}}$ & $3.34 \pm 0.08^{\mathrm{cD}}$ & $1.75 \pm 0.05^{\mathrm{bD}}$ & $2.07 \pm 0.04^{\mathrm{aD}}$ \\
\hline Jingfen 02 & $18.38 \pm 1.23^{\mathrm{dB}}$ & $6.43 \pm 0.18^{\mathrm{cC}}$ & $3.02 \pm 0.20^{\mathrm{aA}}$ & $3.92 \pm 0.25^{\mathrm{bB}}$ & $4.45 \pm 0.08^{\mathrm{dAB}}$ & $3.32 \pm 0.01^{\mathrm{cD}}$ & $1.15 \pm 0.04^{\mathrm{bA}}$ & $1.41 \pm 0.04^{\mathrm{aE}}$ \\
\hline Fenghonggu & $19.87 \pm 0.32^{\mathrm{cC}}$ & $5.13 \pm 0.18^{\mathrm{bA}}$ & $3.98 \pm 0.33^{\mathrm{aB}}$ & $4.87 \pm 0.29^{\mathrm{bC}}$ & $4.58 \pm 0.25^{\mathrm{dBC}}$ & $2.74 \pm 0.02^{\mathrm{aA}}$ & $2.04 \pm 0.05^{\mathrm{cCE}}$ & $2.39 \pm 0.03^{b F}$ \\
\hline
\end{tabular}

The results were expressed as $\mu \mathrm{mol}$ Trolox equivalents/g dry weight ( $\mu \mathrm{mol} \mathrm{TE} / \mathrm{g} \mathrm{DW})$. Values are means $\pm \mathrm{SD}$ of three determinations.

The different lowercase letters indicate significant differences within different processing methods of the same cultivar $(P<0.05)$. The different uppercase letters indicate significant differences within different cultivars with the same treatment $(P<0.05)$.

(b)

\begin{tabular}{lcccccccc}
\hline \multirow{2}{*}{ Foxtail millet } & \multicolumn{4}{c}{ ABTS } & & \multicolumn{2}{c}{ ORAC } \\
& Whole & Dehulled & Steamed & Cooked & Whole & Dehulled & Steamed & Cooked \\
\hline Longg12 & $47.79 \pm 3.46^{\mathrm{cC}}$ & $11.34 \pm 0.28^{\mathrm{bA}}$ & $4.34 \pm 0.28^{\mathrm{aA}}$ & $6.56 \pm 0.19^{\mathrm{aC}}$ & $465.1 \pm 39.88^{\mathrm{cB}}$ & $136.8 \pm 3.26^{\mathrm{aD}}$ & $193.5 \pm 17.47^{\mathrm{bC}}$ & $144.4 \pm 0.47^{\mathrm{aE}}$ \\
Jigu31 & $59.92 \pm 0.04^{\mathrm{dD}}$ & $14.41 \pm 0.31^{\mathrm{cB}}$ & $4.93 \pm 0.22^{\mathrm{aB}}$ & $6.67 \pm 0.12^{\mathrm{bC}}$ & $624.1 \pm 2.79^{\mathrm{dD}}$ & $123.0 \pm 0.77^{\mathrm{bCD}}$ & $133.7 \pm 0.72^{\mathrm{cB}}$ & $102.5 \pm 6.62^{\mathrm{aC}}$ \\
Yugu01 & $41.76 \pm 3.14^{\mathrm{cA}}$ & $15.24 \pm 0.36^{\mathrm{bC}}$ & $5.45 \pm 0.04^{\mathrm{aC}}$ & $3.69 \pm 0.29^{\mathrm{aA}}$ & $537.5 \pm 34.89^{\mathrm{cC}}$ & $182.2 \pm 40.21^{\mathrm{bE}}$ & $202.1 \pm 2.35^{\mathrm{bC}}$ & $101.0 \pm 4.26^{\mathrm{aC}}$ \\
Jinggu21 & $48.12 \pm 2.41^{\mathrm{cC}}$ & $9.53 \pm 0.06^{\mathrm{bD}}$ & $6.33 \pm 0.38^{\mathrm{aD}}$ & $6.37 \pm 0.24^{\mathrm{aC}}$ & $486.0 \pm 33.98^{\mathrm{cB}}$ & $90.68 \pm 2.73^{\mathrm{aB}}$ & $128.6 \pm 10.76^{\mathrm{bB}}$ & $113.1 \pm 2.84^{\mathrm{abD}}$ \\
Jingfen02 & $45.04 \pm 2.81^{\mathrm{cBC}}$ & $11.88 \pm 0.79^{\mathrm{bE}}$ & $5.01 \pm 0.06^{\mathrm{aB}}$ & $4.29 \pm 0.21^{\mathrm{aB}}$ & $423.0 \pm 30.67^{\mathrm{bA}}$ & $111.6 \pm 6.54^{\mathrm{aBC}}$ & $111.4 \pm 0.58^{\mathrm{aA}}$ & $91.0 \pm 6.55^{\mathrm{aB}}$ \\
Fenghonggu & $44.43 \pm 1.11^{\mathrm{dAB}}$ & $10.30 \pm 0.07^{\mathrm{cF}}$ & $7.10 \pm 0.42^{\mathrm{aE}}$ & $8.61 \pm 0.55^{\mathrm{bD}}$ & $414.6 \pm 20.59^{\mathrm{cA}}$ & $71.6 \pm 1.77^{\mathrm{aA}}$ & $103.0 \pm 2.21^{\mathrm{bA}}$ & $82.7 \pm 0.55^{\mathrm{aA}}$ \\
\hline
\end{tabular}

The results were expressed as $\mu \mathrm{mol}$ Trolox equivalents/g dry weight ( $\mu \mathrm{mol}$ TE/g DW). Values are means \pm SD of three determinations.

The different lowercase letters indicate significant differences within different processing methods of the same cultivar $(P<0.05)$. The different uppercase letters indicate significant differences within different cultivars with the same treatment $(P<0.05)$.

(c)

\begin{tabular}{|c|c|c|c|c|}
\hline \multirow{2}{*}{ Millet } & \multicolumn{4}{|c|}{ APC } \\
\hline & Whole & Dehulled & Steamed & Cooked \\
\hline Longg12 & 0.82 & 0.29 & 0.21 & 0.23 \\
\hline Jigu31 & 1.00 & 0.34 & 0.19 & 0.20 \\
\hline Yugu01 & 0.78 & 0.42 & 0.19 & 0.21 \\
\hline Jinggu21 & 0.83 & 0.31 & 0.21 & 0.22 \\
\hline Jingfen02 & 0.76 & 0.33 & 0.15 & 0.17 \\
\hline Fenghonggu & 0.78 & 0.28 & 0.22 & 0.24 \\
\hline
\end{tabular}

TABLE 3: Pearson's correlation coefficients of antioxidant activities, phytic acid, total phenolics, total flavonoid content, and cinnamic acid.

\begin{tabular}{lcccc}
\hline & ORAC & FRAP & ABTS & DPPH \\
\hline ORAC & 1.00 & & & \\
FRAP & $0.95^{* *}$ & 1.00 & & \\
ABTS & $0.96^{* *}$ & $0.99^{* *}$ & 1.00 & \\
DPPH & $0.79^{* *}$ & $0.88^{* *}$ & $0.89^{* *}$ & 1.00 \\
CA & $0.75^{* *}$ & $0.83^{* *}$ & $0.86^{* *}$ & $0.89^{* *}$ \\
PA & $0.61^{* *}$ & $0.70^{* *}$ & $0.72^{* *}$ & $0.72^{* *}$ \\
TPH & $0.87^{* *}$ & $0.91^{* *}$ & $0.91^{* *}$ & $0.83^{* *}$ \\
\hline
\end{tabular}

TPC $=$ total phenolics, $\mathrm{PA}=$ phytic acid, $\mathrm{CA}=$ cinnamic acid, and $* *=$ significant at $P<0.01$. millet demonstrated remarkable radical scavenging capacity, which was associated with its high contents of natural antioxidants found in the samples, such as phenolic compounds, cinnamic acid, and phytic acid. Correlations between the antioxidant activity and CA ranged from 0.75 to 0.89 , while the antioxidant activity and total phenolic content ranged from 0.83 to 0.91 . Therefore, cooked millet was a good choice for human.

\section{Additional Points}

Practical Applications. The foxtail millet mainly in arid and semiarid regions is one of the major food crops in northern China. Steaming and cooking are two main homely cuisine 
ways in China or other countries. Moreover, phenolic compounds of millet, presented in free and bound forms, are ubiquitous and beneficial to human health. Therefore, we research the effect of steaming and cooking on the phenolic content and antioxidant activity, in order to determine a good processing way for millet. Then, for the steamed and cooked millet, we can establish optimal conditions to improve the retention rate of TPC in the further research. Lastly, for the dehulled millet, we can develop an effective method of millet dehulling to improve the retention rate of TPC in the further research.

\section{Conflicts of Interest}

All authors declare that they have no conflicts of interest regarding the publication of this paper.

\section{Acknowledgments}

The authors acknowledge the financial support of the Special Fund for Grain Research in the Public Interest (201313011-64, 201513003-8), the China National Natural Science Foundation (31371812, 31571878), the Science and Technology Infrastructure Program of Jiangsu (BM2014051/004), the Open Project Program of State Key Laboratory of Dairy Biotechnology, Bright Dairy \& Food Co. Ltd. (SKLDB201305, SKLDB2016-003), the Scientific Research and Technological Development Program of Guangxi (GKH14251003), the Six-Talent Peaks Project in Jiangsu Province, and Qing Lan Project, which has enabled them to carry out this study.

\section{References}

[1] Li Yu and Wu Shuzhi, "Traditional maintenance and multiplication of foxtail millet (Setaria italica (L.) P.Beauv.) landraces in China," Euphytica, vol. 87, no. 1, pp. 33-38, 1996.

[2] N. Sreenivasulu, M. Miranda, H. S. Prakash, U. Wobus, and W. Weschke, "Transcriptome changes in foxtail millet genotypes at high salinity: identification and characterization of a PHGPX gene specifically up-regulated by $\mathrm{NaCl}$ in a salt-tolerant line," Journal of Plant Physiology, vol. 161, no. 4, pp. 467-477, 2004.

[3] V. Viswanath, A. Urooj, and N. G. Malleshi, "Evaluation of antioxidant and antimicrobial properties of finger millet polyphenols (Eleusine coracana)," Food Chemistry, vol. 114, no. 1, pp. 340-346, 2009.

[4] Y. Choi, H.-S. Jeong, and J. Lee, "Antioxidant activity of methanolic extracts from some grains consumed in Korea," Food Chemistry, vol. 103, no. 1, pp. 130-138, 2007.

[5] P. Singh and S. Srivastava, "Nutritional composition of sixteen new varieties of fingermillet," Journal of Community Mobilization and Sustainable Development, vol. 1, pp. 81-84, 2006.

[6] K. Bachar, E. Mansour, A. B. Khaled et al., "Fiber content and mineral composition of the finger millet of the Oasis of Gabes Tunisia," Journal of Agricultural Science, vol. 5, no. 2, pp. 219226, 2013.

[7] A. Chandrasekara and F. Shahidi, "Content of insoluble bound phenolics in millets and their contribution to antioxidant capacity," Journal of Agricultural and Food Chemistry, vol. 58, no. 11, pp. 6706-6714, 2010.
[8] E. Ivanišová, M. Ondrejovič, and S. Šilhár, "Antioxidant activity of milling fractions of selected cereals," Nova Biotechnologica et Chimica, vol. 11, no. 1, pp. 45-56, 2012.

[9] E. Ivanišová, M. Ondrejovič, and S. Šilhár, "Antioxidant activity of milling fractions of selected cereals," Nova Biotechnologica et Chimica, vol. 11, no. 1, pp. 45-56, 2012.

[10] J. R. N. Taylor, P. S. Belton, T. Beta, and K. G. Duodu, "Increasing the utilisation of sorghum, millets and pseudocereals: developments in the science of their phenolic phytochemicals, biofortification and protein functionality," Journal of Cereal Science, vol. 59, no. 3, pp. 257-275, 2014.

[11] J. R. Taylor and K. G. Duodu, "Effects of processing sorghum and millets on their phenolic phytochemicals and the implications of this to the health-enhancing properties of sorghum and millet food and beverage products," Journal of the Science of Food and Agriculture, vol. 95, no. 2, pp. 225-237, 2015.

[12] L. Z. Zhang and R. H. Liu, "Phenolic and carotenoid profiles and antiproliferative activity of foxtail millet," Food Chemistry, vol. 174, pp. 495-501, 2015.

[13] R. Shen, S. Yang, G. Zhao, Q. Shen, and X. Diao, "Identification of carotenoids in foxtail millet (Setaria italica) and the effects of cooking methods on carotenoid content," Journal of Cereal Science, vol. 61, pp. 86-93, 2015.

[14] S. Soponronnarit, A. Nathakaranakule, A. Jirajindalert, and C. Taechapairoj, "Parboiling brown rice using super heated steam fluidization technique," Journal of Food Engineering, vol. 75, no. 3, pp. 423-432, 2006.

[15] N. Rahmani and H. G. Muller, "The fate of thiamin and riboflavin during the preparation of couscous," Food Chemistry, vol. 55, no. 1, pp. 23-27, 1996.

[16] B. J. Xu and S. K. C. Chang, "A comparative study on phenolic profiles and antioxidant activities of legumes as affected by extraction solvents," Journal of Food Science, vol. 72, no. 2, pp. S159-S166, 2007.

[17] K. K. Adom and R. H. Liu, "Antioxidant activity of grains," Journal of Agricultural and Food Chemistry, vol. 50, no. 21, pp. 6182-6187, 2002.

[18] V. L. Singleton, R. Orthofer, and R. M. Lamuela-Raventós, "Analysis of total phenols and other oxidation substrates and antioxidants by means of folin-ciocalteu reagent," Methods in Enzymology, vol. 299, pp. 152-178, 1999.

[19] M. H. Badau, I. Nkama, and I. A. Jideani, "Phytic acid content and hydrochloric acid extractability of minerals in pearl millet as affected by germination time and cultivar," Food Chemistry, vol. 92, no. 3, pp. 425-435, 2005.

[20] E. Wheeler and R. Ferrel, "A method for phytic acid determination in wheat and wheat fractions," Cereal Chemistry, vol. 48, pp. 312-320, 1971.

[21] M. B. Arnao, A. Cano, and M. Acosta, "The hydrophilic and lipophilic contribution to total antioxidant activity," Food Chemistry, vol. 73, no. 2, pp. 239-244, 2001.

[22] K. Thaipong, U. Boonprakob, K. Crosby, L. Cisneros-Zevallos, and D. H. Byrne, "Comparison of ABTS, DPPH, FRAP, and ORAC assays for estimating antioxidant activity from guava fruit extracts," Journal of Food Composition and Analysis, vol. 19, no. 6-7, pp. 669-675, 2006.

[23] W. Brand-Williams, M. E. Cuvelier, and C. Berset, "Use of a free radical method to evaluate antioxidant activity," $L W T$-Food Science and Technology, vol. 28, no. 1, pp. 25-30, 1995.

[24] D. Huang, B. Ou, M. Hampsch-Woodill, J. A. Flanagan, and R. L. Prior, "High-throughput assay of oxygen radical absorbance 
capacity (ORAC) using a multichannel liquid handling system coupled with a microplate fluorescence reader in 96-well format," Journal of Agricultural and Food Chemistry, vol. 50, no. 16, pp. 4437-4444, 2002.

[25] K.-H. Kim, R. Tsao, R. Yang, and S. W. Cui, "Phenolic acid profiles and antioxidant activities of wheat bran extracts and the effect of hydrolysis conditions," Food Chemistry, vol. 95, no. 3, pp. 466-473, 2006.

[26] M. Vaher, K. Matso, T. Levandi, K. Helmja, and M. Kaljurand, "Phenolic compounds and the antioxidant activity of the bran, flour and whole grain of different wheat varieties," Procedia Chemistry, vol. 2, pp. 76-82, 2010.

[27] C. M. Mcdonough, L. W. Rooney, and S. O. Serna-Saldivar, "The millets," in Handbook of Cereal Science and Technology, Food Science and Technology, pp. 177-202, Marcel Dekker, New York, NY, USA, 2000.

[28] B.-Q. Cai, P. Yu, H.-B. He, and Q.-J. Wu, "The extraction technology and property characterization of flavonoids in the husk of paddy rice," Acta Agriculturae Universitatis Jiangxiensis, vol. 29, no. 1, pp. 142-147, 2007.

[29] S. Chowdhury and D. Punia, "Nutrient and antinutrient composition of pearl millet grains as affected by milling and baking," Nahrung_Food, vol. 41, no. 2, pp. 105-107, 1997.

[30] H. Sartelet, S. Serghat, A. Lobstein et al., "Flavonoids extracted from fonio millet (Digitaria exilis) reveal potent antithyroid properties," Nutrition, vol. 12, no. 2, pp. 100-106, 1996.

[31] E. Gaitan, "Goitrogens in food and water," Annual Review of Nutrition, vol. 10, pp. 21-39, 1990.

[32] M. E. El Hag, A. H. El Tinay, and N. E. Yousif, "Effect of fermentation and dehulling on starch, total polyphenols, phytic acid content and in vitro protein digestibility of pearl millet," Food Chemistry, vol. 77, no. 2, pp. 193-196, 2002.

[33] A. Bassiri and A. Nahapetian, "Differences in concentrations and interrelationships of phytate, phosphorus, magnesium, calcium, zinc, and iron in wheat varieties grown under dryland and irrigated conditions," Journal of Agricultural and Food Chemistry, vol. 25, no. 5, pp. 1118-1122, 1977.

[34] D. W. Griffiths, "The phytate content and iron-binding capacity of various field bean (Vicia faba) preparations and extracts," Journal of the Science of Food and Agriculture, vol. 33, no. 9, pp. 847-851, 1982.

[35] D. E. C. Crean and D. R. Haisman, "The interaction between phytic acid and divalent cations during the cooking of dried peas," Journal of the Science of Food and Agriculture, vol. 14, no. 11, pp. 824-833, 1963.

[36] K. Saio, E. Koyama, and T. Watanabe, "Protein-calcium-phytic acid relationships in soybean: Part I. Effects of calcium and phosphorus on solubility characteristics of soybean meal protein," Agricultural and Biological Chemistry, vol. 31, no. 10, pp. 1195-1200, 1967.

[37] M. Ozgen, R. N. Reese, A. Z. Tulio Jr., J. C. Scheerens, and A. R. Miller, "Modified 2,2-azino-bis-3-ethylbenzothiazoline-6sulfonic acid (ABTS) method to measure antioxidant capacity of selected small fruits and comparison to ferric reducing antioxidant power (FRAP) and 2,2l-diphenyl-1- picrylhydrazyl (DPPH) methods," Journal of Agricultural and Food Chemistry, vol. 54, no. 4, pp. 1151-1157, 2006.

[38] N. P. Seeram, M. Aviram, Y. Zhang et al., "Comparison of antioxidant potency of commonly consumed polyphenol-rich beverages in the United States," Journal of Agricultural and Food Chemistry, vol. 56, no. 4, pp. 1415-1422, 2008.
[39] J. M. Awika, L. W. Rooney, X. Wu, R. L. Prior, and L. CisnerosZevallos, "Screening methods to measure antioxidant activity of sorghum (Sorghum bicolor) and sorghum products," Journal of Agricultural and Food Chemistry, vol. 51, no. 23, pp. 6657-6662, 2003.

[40] M. Moreno-Montoro, M. Olalla-Herrera, R. GimenezMartinez, M. Navarro-Alarcon, and J. A. Rufián-Henares, "Phenolic compounds and antioxidant activity of Spanish commercial grape juices," Journal of Food Composition and Analysis, vol. 38, pp. 19-26, 2015. 

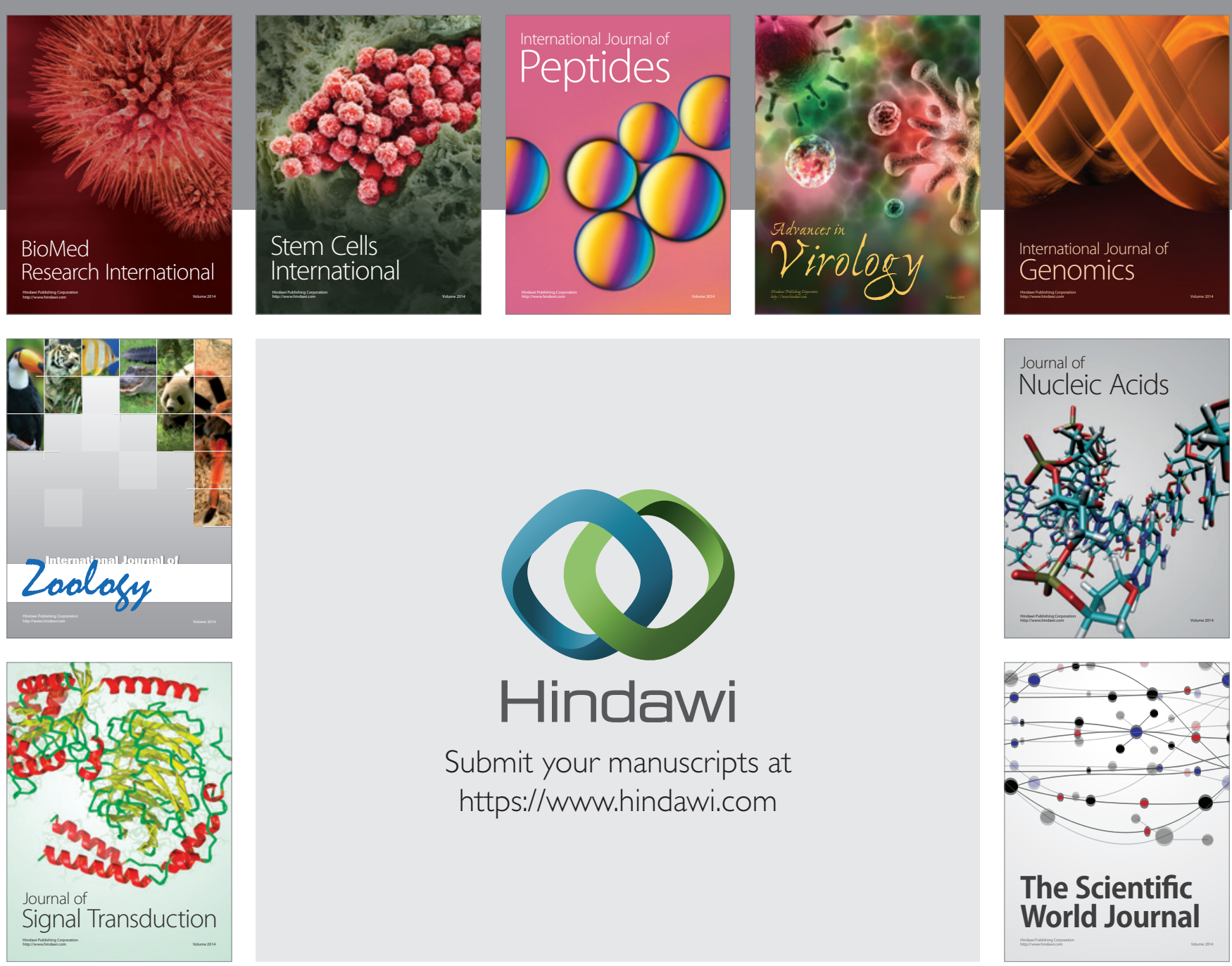

Submit your manuscripts at

https://www.hindawi.com
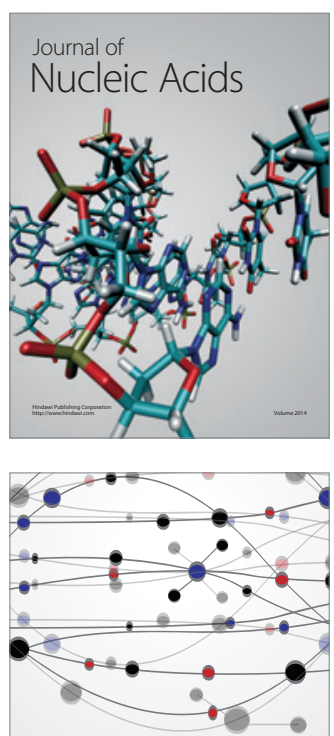

The Scientific World Journal
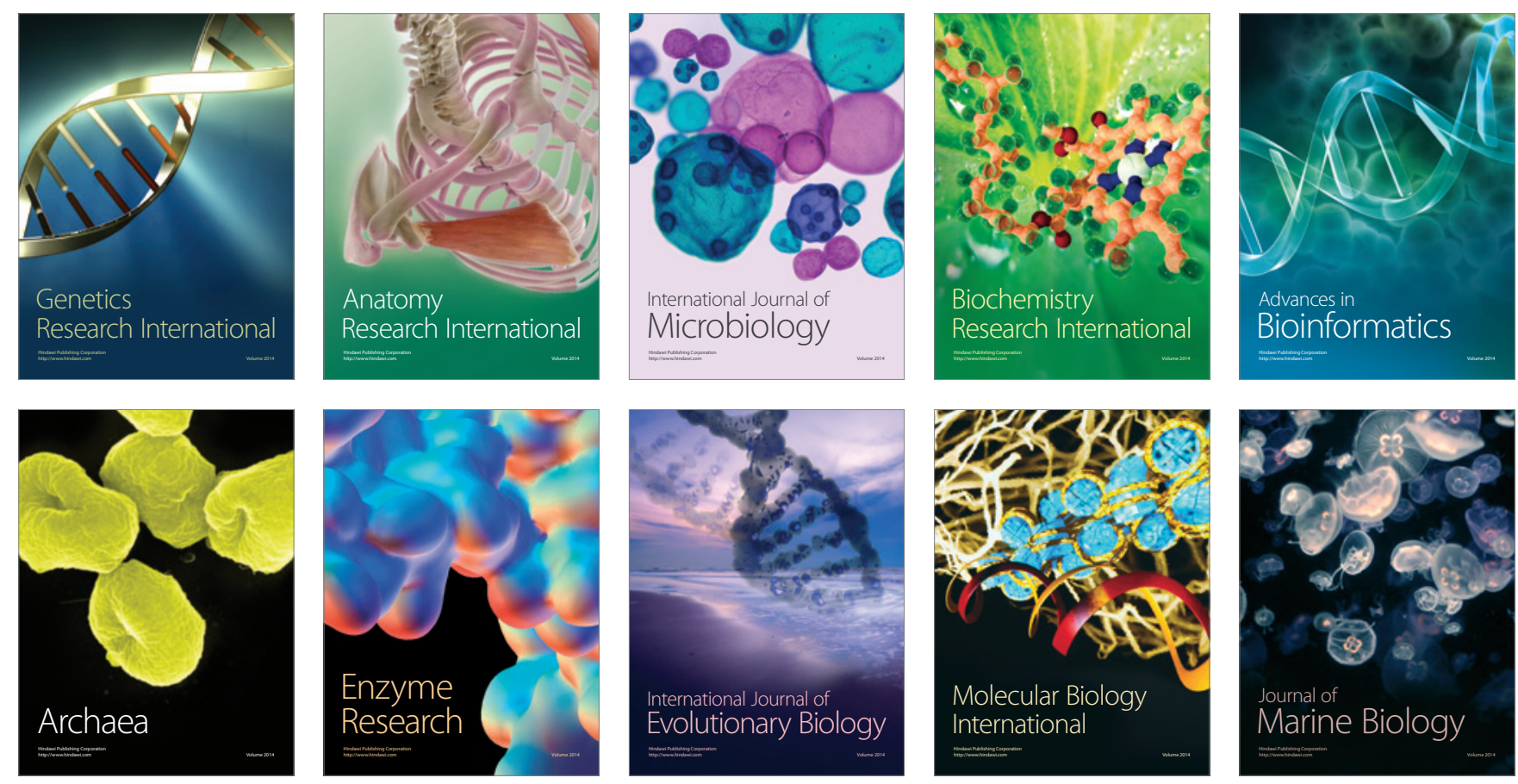